\title{
The relationship between sleep quality and physical activity among patients with heart failure: a cross-sectional study
}

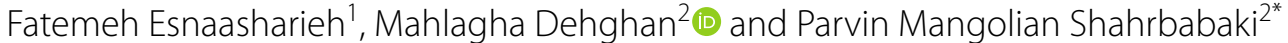

\begin{abstract}
Background: Sleep disorders are one of the most common and annoying problems among patients with heart failure, which decrease their quality of life. Participation in physical activity is one of the most effective methods to reduce sleep disorders; however, few patients participate. This study was conducted to examine the relationship between physical activities and sleep quality among heart failure patients.
\end{abstract}

Methods: A convenience sample of 100 patients with heart failure referred to rehabilitation centers in southeastern Iran was used in this descriptive cross-sectional study. The Pittsburgh Sleep Quality Index and the Rapid Assessment of Physical Activity (RAPA) were used to collect data. The Spearman correlation coefficient and regression were used to analyze the data. The significance level was $<0.05$.

Results: The results revealed that the mean score of sleep quality was $8.74 \pm 2.83$, with the majority of them (84.47\%) having poor sleep quality. The mean score of physical activity was $2.59 \pm 1.33$, and the majority of them (95.15\%) had sub-optimal physical activity. There was a significant and inverse relationship between the total scores of sleep quality and physical activity, and patients' sleep quality improved while physical activity increased. Physical activity, sex, history of heart surgery, and the stage of illness were found to account for $31 \%$ of the variances in patients' sleep quality.

Conclusion: The results of this study showed better sleep quality among patients who were more physically active. Given that the majority of patients with heart failure suffer from sleep disorders, patients' knowledge of physical activity should be increased to improve their quality of sleep and quality of life.

Keywords: Physical activity, Sleep quality, Heart failure

\section{Introduction}

In most countries around the world, heart failure is one of the leading causes of disability [1]. It is estimated that by 2030, the global rate of heart disease mortality will have risen to more than 23.3 million people [2]. Patients with heart failure who have a decreased functional capability, dyspnea, and disability face numerous problems, including sleep disorders [3].

*Correspondence: mangolian167@yahoo.com

${ }^{2}$ Nursing Research Center, Razi Faculty of Nursing and Midwifery, Kerman University of Medical Sciences, Haft-Bagh Highway, Kerman, Iran

Full list of author information is available at the end of the article
Sleep disorder is one of the most common problems among patients with heart failure, and their sleep quality is considered a basic care requirement [4]. Deprivation of good sleep increases the secretion of catecholamine, blood pressure, the amount of oxygen needed by the heart, and ultimately increases the burden on the heart; therefore, it leads to many physical and mental problems as well as a decrease in the quality of life [5]. It seems that lifestyle can affect the symptoms of heart failure such as sleep disorders [6]. However, limitations in lifestyle, social isolation and mood disorders make these patients unable to enjoy adequate and quality sleep [7]. original author(s) and the source, provide a link to the Creative Commons licence, and indicate if changes were made. The images or other third party material in this article are included in the article's Creative Commons licence, unless indicated otherwise in a credit line to the material. If material is not included in the article's Creative Commons licence and your intended use is not permitted by statutory regulation or exceeds the permitted use, you will need to obtain permission directly from the copyright holder. To view a copy of this licence, visit http://creativecommons.org/licenses/by/4.0/. The Creative Commons Public Domain Dedication waiver (http://creativeco mmons.org/publicdomain/zero/1.0/) applies to the data made available in this article, unless otherwise stated in a credit line to the data. 
Today, physical activity is one of the simplest and possibly the most inexpensive strategies for improving the lifestyle of cardiovascular patients [8]. Physical activity is any physical movement that requires energy expenditure and is generated by skeletal muscle [9]. Physical activity can moderate risk factors in heart failure patients [10]. Patients can do more activities without becoming tired or short of breath, and improves their quality of life because physical activity improves muscle tone, strengthens the heart muscle and cardiovascular system, which improves the heart's ability to pump, improves circulation and helps the body use oxygen better and increase energy levels [11]. Regular physical activity can also help sleep better, as it can increase sleep duration, improve sleep quality, and reduce the onset of sleep or the time it takes to fall asleep [12]. However, most heart failure patients do not engage in long-term and regular physical activity [13].

According to reports, heart failure patients' physical activity is on average $16 \%$ lower than that of healthy people [14]. It seems that lack of knowledge about selfcare and inadequate care at home makes heart failure patients unaware of the importance of physical activity [15]. Even patients with heart failure believe they must rest and do not engage in physical activity after admission to hospital [16]. Therefore, it is important to study the relationship between physical activities and sleep quality and their effects on the quality of life of heart failure patients.

The prevalence of heart failure in Iran is posing a serious challenge to the Iranian health system [17]. Between 29 and $47 \%$ of patients are readmitted within 3-6 months of their initial discharge, while $50 \%$ of readmissions are avoidable [18]. On the other hand, insufficient physical activity is a concern in Iranian society, particularly among Iranian adults [19]. Thirty to seventy percent of Iranian patients with cardiac diseases, like the rest of the population, do not engage in enough physical activity [20]. Another issue is that $56 \%$ of Iranian patients with heart failure suffer from sleep disorders and have to take sleeping pills [21]. A review of the literature shows that physical activity, regardless of its mode and intensity, has increased sleep efficiency, especially in patients on hemodialysis, with diabetes, sleep apnea, obesity, cancer, and rheumatoid arthritis [22-27].

In view of the above, it seems that physical activity among patients with heart failure has been neglected and the problems of patients with heart failure especially sleep disorder and its related factors should be given more attention. In addition, physical activity and sleep habits can be influenced by the culture and customs of societies, which have not been studied in Iran; therefore, this study was performed to investigate the relationship between sleep quality and physical activity among patients with heart failure.

\section{Method \\ Study design and setting}

The current research was a cross-sectional descriptive correlational study on patients with heart failure referred to cardiac rehabilitation centers affiliated to Jahrom University of Medical Sciences in southeast Iran with a code of ethics (IR.KMU.REC.1399.269) from Kerman University of Medical Sciences and guideline for reporting observational studies (STROBE). This study lasted from October to January 2020.

\section{Sample and sampling}

Considering correlation coefficient $(-0.391)$, 95\% confidence and $90 \%$ test power, 61 samples were calculated, but with an effect size of 1.5, 110 eligible patients admitted to cardiac rehabilitation centers were recruited by the convenience sampling method to minimize the risk of dropout and 103 patients completed the study. The inclusion criteria included patients with stages 2-3 of heart failure diagnosed by a cardiologist [28], patients over the age of 18 who were physically and mentally capable of answering the questionnaire items, and patients in a stable state of the disease. The patients who did not answer to one-third of the questionnaire items and had instable state of the disease were excluded from the study.

\section{Data collection tools}

Data were collected using a demographic information questionnaire, the Pittsburgh Sleep Quality Index (PSQI), and the Rapid Assessment of Physical Activity (RAPA).

\section{Demographic information questionnaire}

patient's age, sex, marital status, occupation, monthly income, level of education, stage of disease, period of illness, other diseases, medications, weight, addiction, history of heart surgery, other chronic illness, and the number of admissions in the previous 6 months or year were all included in the questionnaire.

\section{Pittsburgh sleep quality index (PSQI)}

This questionnaire is used to assess the quality of sleep and contains 19 items rated on a 4-point Likert scale from 0 to 3 . The questionnaire has seven subscales of subjective sleep quality, sleep latency, sleep duration, habitual sleep efficiency, sleep disturbances, use of sleeping medications and daytime dysfunction. The questionnaire total score ranges from 0 to 21 with a score of more than five indicating poor sleep quality. The participant's score in each item would range from 0 to three, indicating no problem at all, moderate problems, serious 
problems and very serious problems, respectively. Using Cronbach's alpha, Buysse et al. (1989), who developed and introduced this questionnaire, obtained an internal consistency of 0.83 . According to their findings, this scale has a sensitivity of $89.6 \%$ and a specificity of $86.5 \%$ in the diagnosis of poor sleep (score $>5$ ). Poor sleep quality was diagnosed with a combination of clinical interviews, structured interviews, and polysomnographic data and compared with the standard score above five [29, 30]. In Iran, the validity of this questionnaire was confirmed by content validity. Split-half reliability was used to measure the consistency of the scores of this questionnaire and Cronbach's alpha coefficient was 0.79 [31].

\section{Rapid assessment of physical activity (RAPA) questionnaire} RAPA assesses the amount and intensity of physical activity and consists of nine items with the response options of yes or no. The first section of the questionnaire defines light, moderate, and vigorous activities for the participants, and the second section includes items about their activities during the week. The RAPA questionnaire consists of seven items that assess the amount, intensity, and duration of physical activity, as well as two items that assess flexibility, strength and the total score of physical activity. The lowest possible score was zero, and the highest possible score was nine. A score of less than six indicates sub-optimal physical activity, while a score of more than six indicates optimal physical activity. To score, choose the question with the highest score with an affirmative response. Any score less than six is suboptimal. Topolski et al. (2006) used the Spearman's rank correlation coefficients to validate the physical activity questionnaire and investigate the relationship between physical activity and energy expenditure. They reported RAPA questionnaire with high sensitivity (81\%), specificity (69\%), and negative predictive value (77\%) [28]. In Iran, this instrument was used by Khajavi and Khanmohamadi (2015). The validity of the tool was confirmed by a confirmatory factor analysis. The reliability of the instrument was obtained with Cronbach's alpha coefficient (0.87) [32].

\section{Data analysis}

Data were analyzed using SPSS25. The demographic and background characteristics of research units, as well as the mean physical activity and sleep quality were described using descriptive statistics (frequency, percentage, mean and standard deviation). The normality of the data distribution was assessed using the KolmogorovSmirnov test. Physical activity score did not follow the normal distribution, but distribution of quality of sleep score was normal; therefore, Spearman correlation coefficient was used to examine the relationship between the overall score of sleep quality and its dimensions and physical activity. Multiple linear regression was used to determine predictors of sleep quality and analyze the relationship between a dependent variable (score of sleep quality) and several independent variables. Physical activity and background variables were entered into regression by backward method and the final model was given in the table. The significance level was considered $P<0.05$.

\section{Results}

The samples had a mean age of $55.98 \pm 11.38$ years. The mean disease duration among the samples was $7.23 \pm 5.03$ years. Table 1 lists the remaining demographic characteristics of the patients.

According to the results, the mean sleep quality of the samples was $8.74 \pm 2.83$. The majority of patients (84.47\%) had poor sleep quality, and among the dimensions of sleep quality, habitual sleep efficiency was the best and sleep duration and sleep disturbances were the worst. Sleep latency (24.27\%) was serious in nearly a quarter of patients, and it was very serious in $23.30 \%$ of them. The majority of them (48.54\%) had no problem with habitual sleep efficiency. $63.11 \%$ of them had serious sleep disorders and $43.69 \%$ of them had no daytime dysfunction. Subjective sleep quality was relatively good in $49.5 \%$ of the patients. However, $38.8 \%$ of them had relatively poor subjective sleep quality. $49.51 \%$ of the patients slept for $6-7 \mathrm{~h}$, while $37.86 \%$ slept for $5-6$ h. $44.66 \%$ had used sleeping medications at least once a week (Table 2). The results showed that the mean physical activity in patients was $2.59 \pm 1.33$ and the majority of patients (95.15\%) had sub-optimal physical activity (Table 3 ).

According to the results, the total score of sleep quality had a significant and inverse relationship with physical activity, meaning that increasing physical activity improved the sleep quality of heart failure patients. A higher sleep quality score indicates poor sleep quality, while a higher physical activity score indicates optimum physical activity due to the inverse sleep score (Table 4). Among the subscales of sleep quality, subjective sleep quality, habitual sleep efficiency, sleep disturbances, use of sleeping medications and daytime dysfunction had a significant and inverse relationship with physical activity. These results revealed that as physical activity increased, sleep quality improved among the subscales described (Table 5).

Based on demographic and background variables, multiple linear regression with backward method was used to predict patients' sleep quality. The patients' sleep quality was considered as a dependent variable. Physical activity, age, BMI, period of illness, sex, marital status, income, substance use, history of heart 
Table 1 Demographic characteristic of the patients $(n=103)$

\begin{tabular}{|c|c|c|}
\hline Variable & $\mathrm{n}$ & $\%$ \\
\hline \multicolumn{3}{|l|}{ Sex } \\
\hline Female & 42 & 40.78 \\
\hline Male & 61 & 59.22 \\
\hline \multicolumn{3}{|l|}{ Marital status } \\
\hline Married & 82 & 79.61 \\
\hline Single/widow/widower/divorced & 21 & 20.39 \\
\hline \multicolumn{3}{|l|}{ Education level } \\
\hline Middle/high school & 52 & 50.49 \\
\hline Diploma & 20 & 19.42 \\
\hline Academic & 31 & 30.09 \\
\hline \multicolumn{3}{|l|}{ Income } \\
\hline$<10$ million Rial & 16 & 15.53 \\
\hline 10-20 million Rial & 21 & 20.39 \\
\hline 20-30 million Rial & 33 & 32.04 \\
\hline > 30 million Rial & 33 & 32.04 \\
\hline \multicolumn{3}{|l|}{ Job } \\
\hline Unemployed & 31 & 30.10 \\
\hline Employed & 72 & 69.90 \\
\hline \multicolumn{3}{|l|}{ Stage of illness } \\
\hline 2 & 23 & 23.33 \\
\hline 3 & 22 & 21.36 \\
\hline 4 & 58 & 56.31 \\
\hline \multicolumn{3}{|l|}{ Substance use } \\
\hline Yes & 14 & 13.59 \\
\hline No & 89 & 86.41 \\
\hline \multicolumn{3}{|l|}{ History of heart surgery } \\
\hline Yes & 21 & 20.39 \\
\hline No & 82 & 79.61 \\
\hline \multicolumn{3}{|l|}{ History of other chronic diseases } \\
\hline Yes & 74 & 71.84 \\
\hline No & 29 & 28.16 \\
\hline \multicolumn{3}{|l|}{ Number of admissions } \\
\hline None & 21 & 20.4 \\
\hline 1 & 37 & 35.9 \\
\hline 2 & 39 & 37.9 \\
\hline 3 days and more & 6 & 5.8 \\
\hline Variable & Mean & SD \\
\hline Age (year) & 55.98 & 11.38 \\
\hline BMI & 27.10 & 4.40 \\
\hline Disease duration (year) & 7.23 & 5.03 \\
\hline
\end{tabular}

surgery, stage of illness, and number of admissions were all independent variables. Following the selection of the best model, the results revealed that physical activity, sex, history of heart surgery, and stage of disease were predictors of patients' sleep quality, accounting for $31 \%$ of the variances in sleep quality. According to beta coefficients, physical activity and sex had an indirect effect. Patients' sleep quality has improved in female sex and as a result of increased physical activity. History of heart surgery and stage of disease had a direct impact. Patients' sleep quality has deteriorated due to a history of heart surgery and increased stage of illness (Table 6). 
Table 2 Sleep quality and its subscales in patients with heart failure $(n=103)$

\begin{tabular}{|c|c|c|}
\hline & $\mathrm{n}$ & $\%$ \\
\hline \multicolumn{3}{|l|}{ Sleep latency } \\
\hline No problem & 19 & 18.45 \\
\hline Moderate problem & 35 & 33.98 \\
\hline Serious problem & 25 & 24.27 \\
\hline Very serious problem & 24 & 23.30 \\
\hline \multicolumn{3}{|l|}{ Habitual sleep efficiency } \\
\hline No problem & 50 & 48.54 \\
\hline Moderate problem & 34 & 33.01 \\
\hline Serious problem & 10 & 9.71 \\
\hline Very serious problem & 9 & 8.74 \\
\hline \multicolumn{3}{|l|}{ Sleep disturbances } \\
\hline No problem & 0 & 0.0 \\
\hline Moderate problem & 38 & 36.89 \\
\hline Serious problem & 65 & 63.11 \\
\hline Very serious problem & 0 & 0.0 \\
\hline \multicolumn{3}{|l|}{ Daytime dysfunction } \\
\hline No problem & 45 & 43.69 \\
\hline Moderate problem & 35 & 33.98 \\
\hline Serious problem & 17 & 16.50 \\
\hline Very serious problem & 6 & 5.83 \\
\hline \multicolumn{3}{|l|}{ Subjective sleep quality } \\
\hline Very good & 8 & 7.77 \\
\hline Relatively good & 51 & 49.51 \\
\hline Relatively bad & 40 & 38.83 \\
\hline Very bad & 4 & 3.88 \\
\hline \multicolumn{3}{|l|}{ Sleep duration } \\
\hline$>7 \mathrm{~h}$ & 0 & 0.0 \\
\hline $6-7 \mathrm{~h}$ & 51 & 49.51 \\
\hline $5-6 h$ & 39 & 37.86 \\
\hline$<5 \mathrm{~h}$ & 13 & 12.62 \\
\hline \multicolumn{3}{|c|}{ Use of sleeping medications } \\
\hline None & 57 & 55.34 \\
\hline Once a week & 17 & 16.50 \\
\hline Twice a week & 29 & 28.16 \\
\hline \multicolumn{3}{|l|}{ Total sleep quality } \\
\hline Normal & 16 & 15.53 \\
\hline Poor & 87 & 84.47 \\
\hline
\end{tabular}

Table 3 Physical activity in patients with heart failure

\begin{tabular}{lrr}
\hline Variable & $\mathbf{n}$ & $\%$ \\
\hline Total physical activity & & \\
Sub-optimal & 98 & 95.15 \\
Optimal & 5 & 4.85 \\
\hline
\end{tabular}

\section{Discussion}

This study aimed to examine the relationship between sleep quality and physical activity among heart failure patients referred to rehabilitation centers in southeastern Iran.

The results showed that the majority of patients had poor sleep quality. A significant proportion of patients had serious and very serious problems in the subscales of sleep latency, habitual sleep efficiency, sleep disturbances, and daytime dysfunction. A large number of patients had poor subjective sleep quality and inadequate sleep duration, and about half of the patients took sleeping medications. Consistent with the results of the current study, Hajj et al. (2020) in the United States, Azevedo et al. (2015) in Brazil, Jorge-Samitier et al. (2020) in Spain, Lainsamputty et al. (2018) in Indonesia, and Zeighami et al. (2013) and Momayyezi et al. (2015) in Iran all found that sleep quality was poor among heart failure patients [4, 33-37]. According to LEE et al. (2016), the majority of heart failure patients had sleep problems three or more times per week in the past month, and less than one-third took sleeping medications in the last week [38]. Abedi et al. (2012) discovered that half of the patients with cardiovascular disease had a good sleep and rest pattern, which contradicted the results of this study [39]. Edmealem et al. (2020) revealed that poor sleep quality was not common in Ethiopian patients with heart failure. The majority of patients slept for more than seven hours, had high habitual sleep efficiency, and did not use sleeping medications [40]. These differences can be attributed to differences in the support provided by heart failure associations, the amount of training provided during discharge, home care, and differences in lifestyle, sociodemographic and cultural status [38-40].

According to the results, majority of the participants had sub-optimal physical activity. Most studies indicate that a significant number of heart failure patients do not engage in physical activities [13, 41]. Fakharzadeh et al. (2015) conducted a systematic study in Iran and found that the majority of heart failure patients did not engage in enough physical activity [20].

The current study results revealed a moderate significant relationship between sleep quality and physical activity among patients with heart failure, implying that patients who did more physical activity had better sleep quality. Furthermore, as physical activity increased, sleep quality improved in all subscales of subjective sleep quality, habitual sleep efficiency, sleep disturbances, the use of sleeping medications, and daytime dysfunction. On the other hand, when patients get enough sleep, they do not feel drowsy during the day, so they can be more active and focus on their work more. It is particularly important to patients who do more regular physical activity, 
Table 4 Descriptive statistics of sleep quality, its subscales and physical activity $(n=103)$

\begin{tabular}{|c|c|c|c|c|c|c|}
\hline Variable & $M$ & SD & Median & IQR (Q3-Q1) & Minimum & Maximum \\
\hline Subjective sleep quality & 1.39 & 0.69 & 1 & $(2-1)$ & 0 & 3 \\
\hline Sleep latency & 1.52 & 1.05 & 1 & $(2-1)$ & 0 & 3 \\
\hline Sleep duration & 1.63 & 0.70 & 2 & $(2-1)$ & 1 & 3 \\
\hline Habitual sleep efficiency & 0.79 & 0.95 & 1 & $(1-0)$ & 0 & 3 \\
\hline Sleep disturbances & 1.63 & 0.48 & 2 & $(2-1)$ & 1 & 2 \\
\hline Use of sleeping medications & 0.93 & 1.21 & 0 & $(2-0)$ & 0 & 3 \\
\hline Daytime dysfunction & 0.84 & 0.90 & 1 & $(1-0)$ & 0 & 3 \\
\hline Total score of sleep quality & 8.74 & 2.83 & 9 & $(11-16)$ & 4 & 16 \\
\hline Physical activity score & 2.59 & 1.33 & 2 & $(2-3)$ & 1 & 7 \\
\hline
\end{tabular}

Table 5 Correlation between sleep quality and physical activity $(n=103)$

\begin{tabular}{lll}
\hline Variable & Physical activity & \\
\cline { 2 - 3 } & $\begin{array}{l}\text { Spearman correlation } \\
\text { coefficient }\end{array}$ & $\boldsymbol{P}$ value \\
& -0.41 & \\
\hline Subjective sleep quality & -0.14 & $<0.001^{* *}$ \\
Sleep latency & -0.15 & 0.16 \\
Sleep duration & -0.21 & 0.14 \\
Habitual sleep efficiency & -0.30 & $0.03^{* *}$ \\
Sleep disturbances & -0.004 & $0.002^{* *}$ \\
Use of sleeping medications & -0.31 & 0.97 \\
Daytime dysfunction & -0.27 & $0.002^{* *}$ \\
Total score of sleep quality & & $0.005^{* *}$ \\
\hline
\end{tabular}

**Significant

because good sleep can involve in the healing and repair of their heart and blood vessels and boosts immune system/function [42]. Studies in this field have also shown that patients who have had more physical activity have had better sleep efficiency and duration, regardless of the type and intensity of activity $[43,44]$. In this regard, Ash et al. (2020) found that everyday physical activity was associated with either longer sleep at the same night or more physical activity on the next day [45]. DuBose and Hadi (2016) showed the long-term impacts of disturbed sleep include lower physical functioning and increased delirium [46].

Paparrigopoulos et al. (2010) discovered that heart failure patients who engaged in moderate to vigorous physical activity were less likely to suffer from sleep disorders compared with cardiac patients with light physical activity [2]. This study clarifies the importance of physical activity among patients with heart failure and can help health care providers improve sleep quality and quality of life by training patients about physical activity.

The results of the study showed that the variables of physical activity, sex, history of heart surgery, and the stage of illness predicted sleep quality in patients with heart failure. Beta coefficients demonstrated that patients' sleep quality improved in women and as a result of an increase in physical activity. Patients' sleep quality decreased due to a history of heart surgery and a high stage of disease. Redeker et al. (2005) discovered a strong relationship between sleep quality and heart failure among patients with chronic heart failure [47]. Alt et al. (2013) demonstrated that women with chronic

Table 6 Multiple linear regression model for all variables and overall sleep quality $(n=103)$

\begin{tabular}{|c|c|c|c|c|c|c|c|}
\hline Independent variable & B & SE & Beta & $\mathbf{t}$ & Sig & $95 \%$ confidence & $\mathrm{R}^{2}$ \\
\hline Constant value & 2.31 & 0.35 & - & 6.53 & $<0.001$ & $(1.61,3.01)$ & 0.310 \\
\hline Physical activity & -0.05 & 0.02 & -0.21 & -2.13 & 0.04 & $(-0.10,0)$ & \\
\hline BMl & -0.02 & 0.01 & -0.18 & -1.90 & 0.06 & $(-0.04,0)$ & \\
\hline Sex & -0.14 & 0.07 & -0.21 & -2.09 & 0.04 & $(-0.27,-0.01)$ & \\
\hline Marital status & 0.14 & 0.08 & 0.17 & 1.83 & 0.07 & $(-0.01,0.30)$ & \\
\hline Substance use & -0.18 & 0.10 & -0.19 & -1.85 & 0.07 & $(-0.38,0.01)$ & \\
\hline History of heart surgery & 0.18 & 0.08 & 0.22 & 2.24 & 0.03 & $(0.02,0.34)$ & \\
\hline Stage of disease & 0.13 & 0.04 & 0.31 & 2.83 & 0.01 & $(0.04,0.21)$ & \\
\hline
\end{tabular}

History of heart surgery: $y e s=1, \mathrm{No}=0$ Marital status: single/widow/widower/divorced $=1$, married $=2$

History of substance use: yes $=1$, No $=0$ Sex: male $=2$, female $=1$ 
rhino sinusitis and those with other diseases had poor sleep quality, which was not strongly associated with the disease severity [48]. They believe that the relationship between disease severity and poor sleep is mutual, and disability predicts worse sleep, which in turn may predict quality of life. It is very important to pay attention to physical activity and quality of sleep in heart failure patients with different demographic characteristics because clinically changes to sleep and physical inactivity in cardiovascular inpatients produce delirium, immunosuppression and depression that may lead to readmission and decrease quality of life [49]. Therefore, it is recommended that health care providers pay attention to this important issue in care planning and lifestyle training.

This study had several limitations. Owing to the fact that temporal and seasonal factors affect the quality of sleep, this cross-sectional study cannot assess the patients' quality of sleep over time and provide objective information about sleep, and it only reflects patients' perceptions of sleep and its quality. The impact of different cut-off on physical activity and sleep may have different results, which is why further studies are recommended. On the other hand, due to the low value of the correlation coefficient in the relationship between the study variables, the existence of a confounding variable may have caused a false or fake correlation, and finally, reverse causality bias may exist.

\section{Conclusion}

The results showed that the sleep quality of the majority of patients with heart failure in this study was poor and their physical activity was not at a desired level. In addition, patients who were more physically active also had better sleep quality. Therefore, it is recommended to take the necessary measures to improve sleep quality by controlling or eliminating the factors that cause sleep disorders, and also to identify the factors affecting patients' compliance with physical activity. It seems that improving the methods of increasing physical activity can be a cost-effective care approach in improving the sleep quality of patients with heart failure.

\section{Acknowledgements}

The present article has been derived from the M.S thesis for critical care nursing. We would thank all patients, the graduate department of Razi Faculty of Nursing and Midwifery of Kerman that helped us in this research.

\section{Authors' contributions}

P.M and F.E contributed in original idea and protocol, conception of the work conducting the study, revising the draft, approval of the final version of the manuscript, and agreed for all aspects of the work. M.D was involved in data analysis, drafting of the manuscript and approval of the final version of the manuscript. All of the authors contributed in the design of the work and revising the draft and approval of the final version of the manuscript.
Funding

The authors declare that there is no funding associated with this project.

\section{Availability of data and materials}

The datasets used and/or analyzed during the current study are available from the corresponding author on reasonable request.

\section{Declarations}

\section{Ethics approval and consent to participate}

The researcher referred to the target medical centers after receiving the code of ethics (IR.KMU.REC.1399.269) from Kerman University of Medical Sciences and a letter of introduction. The researcher took written consent from patients referred to the medical center for rehabilitation after obtaining permission from the authorities of these centers and providing the necessary explanations about the objectives and method of the study. Patients were included in the study after their doctor confirmed that they were in good health and that they were able to answer the questionnaire items, which were asked in the form of interviews and recorded by the researcher.

\section{Consent for publication}

Not applicable.

\section{Competing interests}

The authors declare that they have no competing interests.

\section{Author details}

${ }^{1}$ MS of Critical Care Nursing, Jahrom University of Medical Sciences, Jahrom, Iran. ${ }^{2}$ Nursing Research Center, Razi Faculty of Nursing and Midwifery, Kerman University of Medical Sciences, Haft-Bagh Highway, Kerman, Iran.

Received: 18 June 2021 Accepted: 1 February 2022

Published online: 07 February 2022

\section{References}

1. Mansouriyeh N, Poursharifi H, Sadeghi MRT, Seirafi MR. The relationship between social support and self-care in patients with heart failure: the role of illness related worries as a mediator. CJMB. 2018;5(2):144-8.

2. Baldwin SAS. Coronary heart disease knowledge, health promoting behaviors and perceived benefits and barriers to exercise and healthy eating in Montana females. Montana State University-Bozeman, College of Nursing; 2014.

3. Smeltzer S, Bare B, Hinkle J, Cheever K. Brunner and Suddarth's textbook of medical surgical nursing. Chapter 26 assessment of function, vol. 1. 14th ed. Philadelphia: Lippincott Williams and Wilkins; 2014. p. 685.

4. Hajj J, Mathelier H, Drachman B, Laudanski K. Sleep quality, fatigue, and quality of life in individuals with heart failure. J Nurse Pract. 2020;21(8):461-5.

5. Nayyeri S, Golafrooz M, Sadeghi H, Amini S, Zarrabi L, Rakhshani MH. The effect of the partnership care model on the quality of sleep among patients with heart failure. J Sabzevar Univ Med Sci. 2015;22(3):289-99.

6. Falk K, Patel H, Swedberg K, Ekman I. Fatigue in patients with chronic heart failure-a burden associated with emotional and symptom distress. Eur J Cardiovasc Nurs. 2009;8(2):91-6.

7. McGowan CL, Levy AS, McCartney N, MacDonald MJ. Isometric handgrip training does not improve flow-mediated dilation in subjects with normal blood pressure. Clin Sci. 2007;112(7):403-9.

8. McGowan CL, Levy AS, McCartney N, MacDonald MJ. Isometric handgrip training does not improve flow-mediated dilation in subjects with normal blood pressure. Clin Sci Lond Engl 1979. 2007;112(7):403-9.

9. Salehi F, Dehghan M, Mangolian Shahrbabaki P, Ebadzadeh MR. Effectiveness of exercise on fatigue in hemodialysis patients: a randomized controlled trial. BMC Sports Sci Med Rehabil. 2020;12(1):1-9.

10. Arija V, Villalobos F, Pedret R, Vinuesa A, Timón M, Basora T, Aguas D, Basora J, Domínguez E, Jovani D, et al. Effectiveness of a physical activity program on cardiovascular disease risk in adult primary health-care 
users: the "Pas-a-Pas" community intervention trial. BMC Public Health. 2017;17(1):576.

11. Piercy KL, Troiano RP, Ballard RM, Carlson SA, Fulton JE, Galuska DA, George SM, Olson RD. The physical activity guidelines for Americans. JAMA. 2018;320(19):2020-8.

12. Kredlow MA, Capozzoli MC, Hearon BA, Calkins AW, Otto MW. The effects of physical activity on sleep: a meta-analytic review. J Behav Med. 2015;38(3):427-49.

13. Zores F, Iliou M-C, Gellen B, Kubas S, Berthelot E, Guillo P, Bauer F, Lamblin N, Bosser G, Damy T, et al. Physical activity for patients with heart failure: position paper from the heart failure (GICC) and cardiac rehabilitation (GERS-P) Working Groups of the French Society of Cardiology. Arch Cardiovasc Dis Suppl. 2019:112(11):723-31.

14. O'Donnell J, Smith-Byrne K, Velardo C, Conrad N, Salimi-Khorshidi G, Doherty A, Dwyer T, Tarassenko L, Rahimi K. Self-reported and objectively measured physical activity in people with and without chronic heart failure: UK Biobank analysis. Open Heart. 2020;7(1):e001099.

15. Nikbakht-Nasrabadi A, Shabany-Hamedan M. Providing healthcare services at home-a necessity in Iran: a narrative review article. Iran J Public Health. 2016:45(7):867.

16. Zores F, lliou M-C, Gellen B, Kubas S, Berthelot E, Guillo P, Bauer F, Lamblin N, Bosser G, Damy T. Physical activity for patients with heart failure: position paper from the heart failure (GICC) and cardiac rehabilitation (GERSP) Working Groups of the French Society of Cardiology. Arch Cardiovasc Dis. 2019;112(11):723-31.

17. Ahmadi A, Soori H, Mobasheri M, Etemad K, Khaledifar A. Heart failure, the outcomes, predictive and related factors in Iran. J Mazandaran Univ Med Sci. 2014;24(118):180-8.

18. Talaei M, Sarrafzadegan N, Sadeghi M, Oveisgharan S, Marshall T, Thomas $\mathrm{GN}$, Iranipour R. Incidence of cardiovascular diseases in an Iranian population: the Isfahan Cohort Study. Arch Iran Med. 2013;16(3):138-44.

19. Mohebi F, Mohajer B, Yoosefi M, Sheidaei A, Zokaei H, Damerchilu B, Mehregan A, Shahbal N, Rezaee K, Khezrian M. Physical activity profile of the Iranian population: STEPS survey, 2016. BMC Public Health. 2019:19(1):1-17.

20. Fakhrzadeh H, Djalalinia S, Mirarefin M, Arefirad T, Asayesh H, Safiri S, Samami E, Mansourian M, Shamsizadeh M, Qorbani M. Prevalence of physical inactivity in Iran: a systematic review. J Cardiovasc Thorac Res. 2016;8(3):92.

21. Zeighami Mohammadi S, Shahparian M. Evaluation of sleep problems and its associated factors in male patients with systolic heart failure. QOM Univ Med Sci J. 2012:6(4):64-73.

22. Løppenthin K, Esbensen BA, Jennum P, Østergaard M, Christensen JF, Thomsen T, Bech JS, Midtgaard J. Effect of intermittent aerobic exercise on sleep quality and sleep disturbances in patients with rheumatoid arthritis-design of a randomized controlled trial. BMC Musculoskelet Disord. 2014;15(1):1-8

23. Mendelson M, Borowik A, Michallet AS, Perrin C, Monneret D, Faure $P$, Levy P, Pépin JL, Wuyam B, Flore P. Sleep quality, sleep duration and physical activity in obese adolescents: effects of exercise training. Pediatr Obes. 2016;11(1):26-32

24. Aiello KD, Caughey WG, Nelluri B, Sharma A, Mookadam F, Mookadam M. Effect of exercise training on sleep apnea: a systematic review and metaanalysis. Respir Med. 2016;116:85-92.

25. Keser I, Özdemir K, Erer D, Onurlu I, Bezgin S. Differences in pain, fatigue, and quality of life in patients with chronic venous insufficiency based on physical activity level. Turk Gogus Kalp Damar Cerrahisi Derg. 2020;28(1):76-83.

26. Du S, Dong J, Zhang H, Jin S, Xu G, Liu Z, Chen L, Yin H, Sun Z. Taichi exercise for self-rated sleep quality in older people: a systematic review and meta-analysis. Int J Nurs Stud. 2015;52(1):368-79.

27. Bernard P, Ivers H, Savard M-H, Savard J. Temporal relationships between sleep and physical activity among breast cancer patients with insomnia. Health Psychol. 2016;35(12):1307.

28. Topolski TD, LoGerfo J, Patrick DL, Williams B, Walwick J, Patrick MB. The rapid assessment of physical activity (RAPA) among older adults. Prev Chronic Dis. 2006;3(4):A118.

29. Buysse DJ, Reynolds CF, Monk TH, Berman SR, Kupfer DJ. The Pittsburgh Sleep Quality Index: a new instrument for psychiatric practice and research. Psychiatry res. 1989;28(2):193-213.
30. Heidari A, Ehteshamzadeh P, Marashi M. Relationship between severity of insomnia, sleep quality, drowsiness, and mental health disorder with academic performance in girls. SRQWC. 2010;2(4):65-76.

31. Heydari A, Ehteshamzadeh P, Marashi M. Relationship between severity of insomnia, sleep quality, drowsiness and mental health disorder with educational performance in girls. J Women Cult Res. 2010;1 (4):65-76.

32. Khajavi D, Khanmohamadi R. The effect of "Green Exercise" on improving the sleep quality of female elderly without regular physical activity in Arak city. J Woman Fam Stud. 2016:3(2):7-32.

33. Azevedo IG, Vieira EMA, Oliveira Neto NR, Nogueira IDB, Melo FES, Nogueira PAMS. Correlation between sleep and quality of life in patients with heart failure. Fisioter Pesqui. 2015;22(2):148-54.

34. Jorge-Samitier P, Durante A, Gea-Caballero V, Antón-Solanas I, FernándezRodrigo MT, Juárez-Vela R. Sleep quality in patients with heart failure in the Spanish population: a cross-sectional study. Int J Environ Res Public Health. 2020;17(21):7772.

35. Lainsamputty F, Chen H-M. The correlation between fatigue and sleep quality among patients with heart failure. NurseLine J. 2018;3(2):100-14

36. Zighami MS, Shahparian M. Evaluation of sleep problems and its associated factors in male patients with systolic heart failure. QOM Univ Med Sci J. 2013;6(4):64-73.

37. Momayyezi M, Fallahzadeh $H$, Barzegar R. Sleep quality in patients with heart failure: comparison between patients and non-patients in Yazd, Iran (2014). Iran Heart J. 2015;16(3):28-37.

38. Lee KS, Lennie TA, Heo S, Song EK, Moser DK. Prognostic importance of sleep quality in patients with heart failure. Am J Crit Care. 2016;25(6):516-25.

39. Abedi H, Bik Mohammadi S, Abdeyazdan G, Nazari H. A survey on the lifestyle of the heart desease patients after discharge from hospital in Urmia Seyyed Alshohada in 2012. Nurs Midwifery J. 2014;11(12):944-54.

40. Edmealem A, Degu SG, Haile D, Gedfew M, Bewket B, Andualem A. Sleep quality and associated factors among diabetes, hypertension, and heart failure patients at Debre Markos referral hospital, Northwest Ethiopia. Sleep Disord. 2020;2020(1):6125845

41. Klompstra L. Physical activity in patients with heart failure: motivations, self-efficacy and the potential of exergaming. Doctoral thesis, comprehensive summary. Linköping: Linköping University Electronic Press; 2016.

42. Faraut B, Boudjeltia KZ, Vanhamme L, Kerkhofs M. Immune, inflammatory and cardiovascular consequences of sleep restriction and recovery. Sleep Med Rev. 2012;16(2):137-49.

43. Paparrigopoulos T, Tzavara C, Theleritis C, Soldatos C, Tountas Y. Physical activity may promote sleep in cardiac patients suffering from insomnia. Int J Cardiol. 2010;143(2):209-11.

44. Dolezal BA, Neufeld EV, Boland DM, Martin JL, Cooper CB. Interrelationship between sleep and exercise: a systematic review. Adv Prev Med. 2017:2017:1364387.

45. Ash G, Jeon S, Conley S, Knies AK, Yaggi HK, Jacoby D, Hollenbeak CS, Linsky S, O'Connell M, Redeker NS. Day-to-day relationships between physical activity and sleep characteristics among people with heart failure and insomnia. Behav Sleep Med. 2021;19(5):602-14.

46. DuBose JR, Hadi K. Improving inpatient environments to support patient sleep. Int J Qual Health Care. 2016;28(5):540-53.

47. Redeker NS, Hilkert R. Sleep and quality of life in stable heart failure.J Cardiac Fail. 2005;11(9):700-4.

48. Alt JA, Smith TL, Mace JC, Soler ZM. Sleep quality and disease severity in patients with chronic rhinosinusitis. Laryngoscope. 2013;123(10):2364-70.

49. Labrosciano C, Tavella R, Reynolds A, Air T, Beltrame JF, Ranasinghe I, Adams RJ. The association between sleep duration and quality with readmissions: an exploratory pilot-study among cardiology inpatients. Clocks Sleep. 2020:2(2):120-42.

\section{Publisher's Note}

Springer Nature remains neutral with regard to jurisdictional claims in published maps and institutional affiliations. 